\title{
A crítica da cobertura jornalística sobre minorias a partir das colunas de ombudsman ${ }^{1}$
}

\section{Criticism of news press coverage about minorities from ombudsman's columns}

Diana de Azeredo²

\footnotetext{
1 Artigo resultante de pesquisa financiada com bolsa da Coordenação de Aperfeiçoamento de Pessoal de Nível Superior (Capes).

2 Jornalista graduada em 2016 pela Universidade de Santa Cruz do Sul (Unisc) e mestre pelo Programa de Pós-Graduação em Jornalismo (PPGJor) da Universidade Federal de Santa Catarina (Ufsc). E-mail: azeredo_diana@yahoo.com.br.
} 


\section{Resumo}

Com base nos conceitos de crítica, reconhecimento e minorias problematizados, respectivamente, em pesquisas de Soares e Silva (2016), Serelle e Sena (2018) e Honneth (2009), este estudo tem como objeto de análise a crítica da cobertura jornalística sobre minorias a partir das colunas de ombudsman do jornal Folha de S.Paulo. Trabalhou-se com 41 textos que fazem a crítica da cobertura do jornal sobre a demanda de indígenas, negros, mulheres e integrantes da comunidade LGBTI+. O objetivo é verificar como o exercício autocrítico se dispõe a debater publicamente esta questão, examinando preconceitos e limitações do próprio jornalismo.

\section{Palavras-chave}

Crítica, ombudsman, reconhecimento, minorias, Folha de S.Paulo.

\section{Abstract}

Based on the concepts of criticism, recognition and minorities, problematized, respectively, on researches by Soares and Silva (2016), Serelle and Sena (2018) and Honneth (2009), this study has as object of analysis the criticism of news press coverage on minorities from the ombudsman's columns of Folha de S.Paulo newspaper. We work with 41 texts with critiques on news press coverage about the demand of indigenous people, blacks, women and members of the LGBTI+ community. The objective is to verify how the self-critical exercise is willing to publicly debate this issue, examining prejudices and limitations of journalism itself.

\section{Keywords}

Criticism, ombudsman, recognition, minorities, Folha de S.Paulo. 


\section{Observações introdutórias sobre as minorias no contexto brasileiro}

O objeto de análise deste artigo é a crítica da cobertura jornalística sobre minorias a partir das colunas de ombudsman do jornal Folha de S.Paulo. Tendo como método a análise de conteúdo, trabalha-se com 41 textos que fazem a crítica da cobertura do jornal sobre a demanda de indígenas, negros, mulheres e integrantes da comunidade $\mathrm{LGBTI}+{ }^{3}$, durante quase trinta anos. O recorte empírico abrange colunas publicadas entre setembro de 1989 e abril de 2019. O objetivo é verificar como o exercício autocrítico se dispõe a debater publicamente o noticiário a respeito de grupos minoritários. Toma-se como base os conceitos de crítica, reconhecimento e minorias problematizados, respectivamente, em pesquisas de Soares e Silva (2016), Serelle e Sena (2018) e Honneth (2009).

De forma preliminar, salienta-se alguns aspectos do contexto brasileiro que, devido às suas peculiaridades, contribuem para justificar algumas escolhas deste estudo. Ainda hoje, mais de cinco séculos após a chegada dos portugueses no país, os assassinatos de indígenas (por meio de doenças e contaminações ou em confrontos diretos com invasores) seguem ocorrendo. Apesar dos avanços no estabelecimento de formas de proteção das terras e das comunidades $^{4}$, os problemas persistem e os primeiros habitantes do Brasil ainda precisam lutar para preservar a própria vida, tentando proteger suas fontes de sustentação e seu patrimônio cultural ${ }^{5}$.

Munduruku (2015) reflete sobre a contemporaneidade desses desafios, salientando os dilemas identitários que os indígenas enfrentam. Ele relata, a orientações sexuais, identidades e expressões de gênero, seguindo recomendação do Manual de Comunicação LGBTI+. Disponível em: http://bit.ly/34fRnH6. Acesso em: 28 abr. 2019. programa Povos Indígenas no Brasil (PIB): http://bit.ly/2BVtusn. Acesso em: 23 abr. 2019. 
partir da própria experiência junto à comunidade mundurucu, no Pará, como, influenciado por imagens negativas disseminadas no ensino escolar, demorou a ter uma percepção a respeito de suas qualidades. "O fato de ser índio ${ }^{6}$ estava ligado a uma série de chavões com que muitas pessoas me insultavam: [...] sujo, preguiçoso, malandro" (MUNDURUKU, 2015, p. 6).

Segundo Munduruku (2015, p. 21), "ainda custa muito caro ser diferente no Brasil neoliberal". Por esse motivo, defende que essa diferença seja cada vez mais mostrada em seu aspecto belo e fundamental no desenvolvimento da sociedade brasileira. "Talvez isso crie uma nova identidade para o povo brasileiro $[\ldots]$, fazendo-o superar a crise instalada em seu meio nestes primeiros quinhentos e tantos anos do nome Brasil" (MUNDURUKU, 2015, p. 12-13).

O fato de os indígenas já terem sido chamados de "negros da terra" (MONTEIRO, 1994) sinaliza as outras vítimas da violência étnica na história nacional?. Capturados e comprados na condição de animais ou mercadorias, os africanos foram trazidos para o outro lado do Atlântico a fim de trabalharem em condições sub-humanas, sem direito à remuneração ou à liberdade. Os mais de trezentos anos de escravidão provocaram dramas profundos, que não foram solucionados, magicamente, com a assinatura da Lei Áurea em 13 de maio de 1888.

Em luta pela própria liberdade, os negros eram considerados rebeldes e violentos. Depois de libertos, mas sem ensino formal e emprego, passaram a ser vistos como propensos a crimes e a vícios. Gomes (2017, p. 104) explica como esse "imaginário racista" tensionou a "regulação-emancipação sociorracial". Ela menciona estudos "científicos" utilizados para ajudar a corroborar as impressões preconceituosas na sociedade.

A identidade se constrói de forma coletiva, por mais que se anuncie individual. No Brasil, o corpo negro ganha visibilidade social na tensão

6 Munduruku (2015, p. 13) alerta que só utilizou o termo "índio" naquele capítulo para exemplificar a situação específica. Em todo o seu livro, ele opta pela palavra "indígena", que designa "nativo" ou "natural da terra". 
entre adaptar-se, revoltar-se ou superar o pensamento racista que o toma por erótico, exótico e violento. Essa superação se dá mediante a publicização da questão racial como um direito, via práticas, projetos, ações políticas, cobrança do Estado e do mundo privado da presença da população negra na mídia, nos cursos superiores, na política, nos lugares de poder e decisão, na moda, na arte, entre outros. (GOMES, 2017, p. 94)

Também vítimas da violência física e simbólica contra seus corpos, as mulheres constituem outro grupo minoritário no país e, igualmente, protagonista de lutas, conquistas e resistências. Ao organizar e publicar registros do movimento feminista brasileiro, Pinto (2003) disponibiliza uma cronologia das ações promovidas, de forma individual e coletiva, com o objetivo de melhorar a condição das mulheres no grande território nacional.

Desde o final do século XIX, inspiradas por conquistas de cidadãs na Europa e nos Estados Unidos, brasileiras passaram a se engajar em iniciativas por direitos políticos, sociais e trabalhistas. Queriam votar e ser votadas, acessar o ensino formal, publicar ideias sobre sexualidade, divórcio e outros tabus e ampliar a igualdade nas fábricas e nos negócios próprios. Saindo da reclusão do lar e avançando para além dos papéis de esposa e mãe, elas começaram a se posicionar contra as "formas hierárquicas e excludentes que regiam as relações entre as pessoas no Brasil" (PINTO, 2003, p. 28-29).

Na virada do século XIX para o XX, o convencimento da opinião pública, por meio de jornais, já era uma vitória a ser obtida. Mesmo em um ambiente adverso, com recursos próprios ou por meio de pequenos espaços obtidos a partir de negociações com homens dispostos ao diálogo, essas mulheres dedicaram esforços para disseminar seus pensamentos emancipatórios nas "franjas da sociedade" (PINTO, 2003, p. 33).

A pesquisadora divide esses primeiros projetos reformistas ou revolucionários em três tipos: as feministas "bem comportadas" e elitistas, que pleiteavam o direito ao voto por meio de congressos e tentativas de negociação com homens que estavam no poder; as intelectuais (professoras, jornalistas...) que se manifestavam por meio de textos e defendiam uma ampliação geral da atuação das mulheres; e as "mal comportadas", inspiradas pelos anarquistas e operários, que lutavam 
por melhores condições de trabalho. É desse terceiro grupo que começa a surgir a noção de que existem diferenças no movimento e "que os oprimidos não são oprimidos da mesma forma" (PINTO, 2003, p. 35).

Entre os membros do movimento LGBTI+ brasileiro, o jornal Lampião da Esquina, fundado em 1978, é um dos marcos no questionamento da primazia do discurso heteronormativo (CANABARRO, 2013). Devido à epidemia de Síndrome da Imunodeficiência Adquirida (Aids) a partir da década de 1980, a luta pela liberdade soma-se à guerra contra o preconceito da mídia que corroborava a ideia de "peste gay" e a batalha pela própria vida - resultando em parcerias com o Estado no estabelecimento de políticas na área da saúde.

"A persistência dos movimentos mundo afora para despatologizar identidades de gênero e orientações afetivo-sexuais se reflete em intenso trabalho de conscientização e resistência", observa Canabarro (2013, p. 3). Ele registra que a homossexualidade foi retirada da classificação de doenças pelo Conselho Federal de Medicina em 1985, significando outra grande conquista para a população LGBTI+ no Brasil - no catálogo da Organização Mundial de Saúde, o termo só foi retirado cinco anos depois. O autor também menciona o surgimento e fortalecimento das instituições dedicadas à causa, à promoção de eventos e às pesquisas na área, além da criação de leis para criminalizar a discriminação de LGBTI+ a partir de 1990.

Canabarro (2013, p. 5) alerta que, "embora se percebam os aparentes avanços, ainda há muito o que resistir e lutar dentro de um quadro recente de ameaças ou perdas efetivas de direitos já conquistados". Conforme o pesquisador, uma das principais metas é a formação de profissionais responsáveis por transmitir informações a um grande público a fim de diminuir o preconceito culturalmente enraizado. Além disso, a união de esforços com outros grupos minoritários como trabalhadores, negros e feministas abre, segundo Canabarro (2013, p. 13), "caminhos para construir um movimento mais abrangente, no que se refere a categorias identitárias".

Para Ribeiro (2017, p. 28), é necessário "desestabilizar e transcender a autorização discursiva branca, masculina cis e heteronormativa e debater como as 
identidades foram construídas". A filósofa defende a problematização dos discursos elaborados a respeito de pessoas que são "antítese de branquitude e masculinidade" (RIBEIRO, 2017, p. 39). Tanto nas produções científicas e midiáticas, existem, lembra ela, manifestações preconceituosas perpetuadas ao longo dos séculos.

"O problema seria quando as diferenças significam desigualdades", ensina Ribeiro (2017, p. 51). A pesquisadora alerta para o risco de "competição de opressões" e propõe o entendimento do quanto "raça, gênero, classe e sexualidade se entrecruzam gerando formas diferentes de experenciar opressões" (RIBEIRO, 2017, p. 71). O desafio é não priorizar determinadas bandeiras minoritárias.

Numa sociedade supremacista branca e patriarcal, mulheres brancas, mulheres negras, homens negros, pessoas transexuais, lésbicas, gays podem falar do mesmo modo que homens brancos cis heterossexuais? Existe o mesmo espaço e legitimidade? Quando existe algum espaço para falar, por exemplo, para uma travesti negra, é permitido que ela fale sobre Economia, Astrofísica, ou só é permitido que fale sobre temas referentes ao fato de ser uma travesti negra? (RIBEIRO, 2017, p. 77)

Ao ressaltar a importância da "quebra de um sistema vigente que invisibiliza essas narrativas" (RIBEIRO, 2017, p. 86), observa que "vozes dissonantes têm conseguido produzir ruídos e rachaduras na narrativa hegemônica" (RIBEIRO, 2017, p. 87). Porém, a violência do silenciamento ainda majoritário, num país onde a maioria da população não é masculina e branca, deve continuar sendo combatida. Segundo Ribeiro (2017, p. 87), "mesmo com essas rachaduras, tornase essencial o prosseguimento do debate estrutural, uma vez que uma coisa não anula a outra".

Freire Filho cita o dicionário de Edgar e Sedgwick (2003, p. 213-214 apud FREIRE FILHO 2004, p. 2) para explicar que minorias é um "conceito que abarca todo grupo social cujas perspectivas e vozes são marginalizadas pelas estruturas de poder e pelos sistemas de significação dominantes numa sociedade ou cultura". Ele situa a crítica sobre as políticas de identidade e representações de grupos oprimidos nos meios de comunicação como um dos temas centrais nos estudos de mídia a partir de 1960. 


\section{Reconhecimento como parâmetro para crítica da cobertura jornalística}

Kellner (2001) desenvolve o entendimento de que os produtos da indústria cultural "são mercadorias que tentam atrair o lucro privado produzido por empresas gigantescas que estão interessadas na acumulação de capital" (KELLNER, 2001, p. 9). Essa busca pela manutenção e aumento das audiências corrobora a criação de determinadas imagens e definições identitárias.

\footnotetext{
O rádio, a televisão, o cinema e os outros produtos da indústria cultural fornecem os modelos daquilo que significa ser homem ou mulher, bemsucedido ou fracassado, poderoso ou impotente. A cultura da mídia também fornece o material com que muitas pessoas constroem o seu senso de classe, de etnia e raça, de nacionalidade, de sexualidade, de "nós" e "eles". (KELLNER, 2001, p. 9).
}

O autor percebe a mídia como um "terreno de disputa" entre diferentes grupos que desejam espaço para as próprias manifestações acerca de identidades e ideologias. Por isso, advoga a favor do aprendizado de "como ler e criticar a mídia" (KELLNER, 2001, p. 10). Segundo ele, que descreve avanços e limitações da teoria crítica e dos estudos culturais, cada perspectiva é válida para auxiliar na compreensão do fenômeno midiático na sociedade. O importante, para Kellner (2001), é ajudar o público a fazer análises críticas a fim de evitar distorções e aumentar o poder das minorias frente aos meios.

A cultura da mídia pode constituir um entrave para a democracia quando reproduz discursos reacionários, promovendo o racismo, o preconceito de sexo, idade, classe e outros, mas também pode propiciar o avanço dos interesses dos grupos oprimidos quando ataca coisas como as formas de segregação racial ou sexual, ou quando, pelo menos, as enfraquece com representações mais positivas de raça e sexo. (KELLNER, 2001, p. 13)

Refletindo sobre a crítica de mídia realizada por acadêmicos, especialistas e leigos, Soares e Silva (2016, p. 11) remetem à "compreensão do jornalismo como produto e produtor de cultura, e ao entendimento da prática noticiosa como experiência cultural". As autoras localizam o potencial da crítica no próprio objeto e além dele: no contexto e na recepção. "Não há possibilidade de se ter 
um consenso sobre os modos de se fazer a crítica de mídia", salientam Soares e Silva (2016, p. 16-17), defendendo que não é possível ignorar a especificidade do objeto, nem a complexidade da sociedade na qual ele está inserido.

A fim de compreender como a ausência e a presença de minorias constituem um parâmetro para a crítica de produtos midiáticos, Serelle e Sena (2018) trabalham com o conceito de reconhecimento (HONNETH, 2009) na análise cinematográfica. "A crítica feita pelos movimentos identitários [...] privilegia o reconhecimento, que se torna critério para análise das ficções. [...] o reconhecimento é uma força motriz em expansão, cada vez mais inclusiva no que se refere à pauta dos grupos subalternizados", explicam Serelle e Sena (2018, p. 18).

Inserindo em uma proposta mais ampla de "teoria da sociedade", Honneth (2009, p. 155) conceitua reconhecimento a partir de uma relação de reciprocidade entre "parceiros de interação, com seus destinatários sociais". Segundo o pensador alemão, as relações de reconhecimento estruturam-se de três formas: primárias (amor, amizade), jurídicas (direitos) e comunidade de valores (solidariedade). Respectivamente, cada forma corresponde à determinada dimensão da personalidade: natureza carencial e afetiva, imputabilidade moral e capacidades/propriedades que, por sua vez, podem ser ameaçadas nos componentes da integridade física, social e dignidade. Quando um grupo não se percebe reconhecido na forma jurídica ou da comunidade de valores, surge uma luta em busca do reconhecimento não efetivado.

[...] são as lutas moralmente motivadas de grupos sociais, sua tentativa coletiva de estabelecer institucional e culturalmente formas ampliadas de reconhecimento recíproco, aquilo por meio do qual vem a se realizar a transformação normativamente gerida nas sociedades. (HONNETH, 2009, p. 156)

Interessa, neste momento, a concepção referente à segunda e à terceira forma de reconhecimento. Para cada uma, Honneth (2009) verifica formas de desrespeito: privação de direitos e exclusão; degradação e ofensa. Quando um grupo, por exemplo, não se vê reconhecido em seus direitos, ele está sendo excluído. Algo semelhante ocorre quando um grupo não se reconhece na solidariedade e não percebe que suas demandas são recebidas de forma solidária - nesse caso, ele está sendo ofendido. 
De acordo com Honneth (2009, p. 216), a privação de direitos e exclusão social estão associadas ao "sentimento de não possuir o status de um parceiro da interação com igual valor, moralmente em pé de igualdade". Já a degradação e a ofensa tiram "dos sujeitos atingidos toda a possibilidade de atribuir um valor social às suas próprias capacidades" (HONNETH, 2009, p. 217). Essas duas categorias serão utilizadas para analisar aspectos criticados na cobertura.

Assumindo o risco de sintetizar um conceito complexo e empregá-lo na análise de um objeto em um contexto bastante específico, parte-se agora para a tentativa de compreensão de como a crítica de ombudsman aborda a cobertura jornalística sobre minorias, considerando as peculiaridades da sociedade brasileira. Trata-se, aqui, do jornal de maior circulação ${ }^{8}$ em um país marcado por lutas de indígenas, negros, mulheres e população LGBTI+ para serem reconhecidos em diferentes níveis. Seria possível, então, considerar o conceito de reconhecimento como parâmetro para criticar a cobertura jornalística? Como o reconhecimento apareceria na crítica?

\section{Indígenas, negros, mulheres e comunidade LGBTI+ nas colunas de ombudsman}

Fundado em 19 de fevereiro de 1921, o jornal Folha de S.Paulo foi o primeiro, na América Latina, a instituir o cargo de ombudsman em setembro de 1989. Atualmente, além da Folha, apenas O Povo conta com esse jornalista que atua como crítico e ouvidor - situação problematizada em publicação recente (AZEREDO, 2019).

Para este artigo, com o objetivo de verificar como o exercício autocrítico se dispõe a debater publicamente a cobertura sobre minorias, foram selecionadas 41 colunas de ombudsman do jornal Folha de S.Paulo - de um total de 1.346 textos publicados aos domingos, de setembro de 1989 a abril de 2019, e disponibilizados no site. Considerou-se somente críticas referentes aos textos informativos (elogios ou críticas de charges, por exemplo, foram descartados). O quadro, a seguir, sintetiza a crítica contida nas colunas. 
Quadro 1: Crítica da cobertura sobre minorias na Folha de S.Paulo

\begin{tabular}{|c|c|}
\hline Data & Problema criticado \\
\hline 21/01/1990 & $\begin{array}{l}\text { Destaque para o prefeito "negro" Mario Barry flagrado com drogas. } \\
\text { https://is.gd/YOM7Og }\end{array}$ \\
\hline 28/01/1990 & $\begin{array}{l}\text { Insistência da redação em seguir se referindo à raça do prefeito, afirmando em nota } \\
\text { que "o crack é uma droga 'cujo comércio e utilização costumam ser associados, social e } \\
\text { culturalmente, aos negros norte-americanos'" (COSTA, 1990). } \\
\text { https://is.gd/FJ1Lwp }\end{array}$ \\
\hline $31 / 03 / 1991$ & $\begin{array}{l}\text { Destaque à reação neoliberal contra a cruzada antipreconceito na mídia, promovida nos } \\
\text { EUA. É como se a Folha estivesse endossando a ideia de que prestar atenção à veiculação } \\
\text { de termos preconceituosos representasse um atentado contra a liberdade de expressão. } \\
\text { https://bit.ly/36myO61 }\end{array}$ \\
\hline 03/05/1992 & $\begin{array}{l}\text { Falta de cobertura do protesto, em Los Angeles, decorrente da absolvição de quatro } \\
\text { policiais acusados de espancar um negro (eles foram absolvidos por juízes brancos e a } \\
\text { Folha só noticiou o resultado do julgamento, sem reportar as reações ao caso). } \\
\text { https://bit.ly/2Wv4RMm }\end{array}$ \\
\hline 25/07/1993 & $\begin{array}{l}\text { Perfil machista, racista e classista de uma "alpinista social". } \\
\text { https://bit.ly/34gQDBv }\end{array}$ \\
\hline 29/08/1993 & $\begin{array}{l}\text { Dificuldade para apurar massacre em aldeia ianomâmi. } \\
\text { https://bit.ly/34dYQX2 }\end{array}$ \\
\hline 07/11/1993 & $\begin{array}{l}\text { Descrição preconceituosa da funcionária do deputado. } \\
\text { https://bit.ly/2PAp9CI }\end{array}$ \\
\hline 29/05/1994 & $\begin{array}{l}\text { Preconceito com o perfil irônico intitulado "A Perua de Deus". } \\
\text { https://bit.ly/2NG3syT }\end{array}$ \\
\hline 05/03/1995 & $\begin{array}{l}\text { Crítica geral à objetificação do corpo feminino e à exaltação da sexualidade durante o } \\
\text { carnaval, sem expor os riscos da violência. } \\
\text { https://bit.ly/2qanCsm }\end{array}$ \\
\hline 02/07/1995 & $\begin{array}{l}\text { Pesquisa sobre racismo considerada "artificial" e quantidade de reportagens sobre } \\
\text { homossexualidade definida como "exagerada". } \\
\text { https://bit.ly/2PzotO7 }\end{array}$ \\
\hline 21/01/1996 & $\begin{array}{l}\text { Falta de abordagem das questões indígenas. } \\
\text { https://bit.ly/2WEXYZj }\end{array}$ \\
\hline 11/07/1999 & $\begin{array}{l}\text { Informação destacada sobre a raça/etnia do novo diretor-geral da PF - considerada racista. } \\
\text { https://bit.ly/2Ny48Ga }\end{array}$ \\
\hline $25 / 03 / 2001$ & $\begin{array}{l}\text { Três reportagens, com viagens a convite do Ministério da Defesa, que parecem defender o } \\
\text { aumento de verbas aos militares (negando acusações de estupros de índios e impactos da } \\
\text { ocupação na fronteira). } \\
\text { https://bit.ly/2BVMIOz }\end{array}$ \\
\hline $26 / 08 / 2001$ & $\begin{array}{l}\text { Invisibilidade e discriminação dos negros na imprensa. } \\
\text { https://bit.ly/34kmbqh }\end{array}$ \\
\hline $30 / 06 / 2002$ & $\begin{array}{l}\text { Preconceito em descrição de foto, identificando "negra do Benin", sendo que não se faria o } \\
\text { mesmo em caso de "branca ou amarela do Benin". } \\
\text { https://bit.ly/2PzDNdG }\end{array}$ \\
\hline $21 / 07 / 2002$ & $\begin{array}{l}\text { Foto de modelo negra era a única sem legenda com o nome. } \\
\text { https://bit.ly/2WuV2OA }\end{array}$ \\
\hline $25 / 04 / 2004$ & $\begin{array}{l}\text { Falta de cobertura sobre conflitos na região da Amazônia (abrangendo nove estados e } \\
60 \% \text { do território nacional). } \\
\text { https://bit.ly/2NvvHzY }\end{array}$ \\
\hline $13 / 02 / 2005$ & $\begin{array}{l}\text { Falta de destaque para a morte de criança indígena, vítima de desnutrição. } \\
\text { https://bit.ly/335NJPV }\end{array}$ \\
\hline 09/07/2006 & $\begin{array}{l}\text { Desequilíbrio da cobertura sobre votação das políticas afirmativas e estatuto da igualdade } \\
\text { racial, com tendências favoráveis ao posicionamento do jornal (contra cotas/estatuto). } \\
\text { https://bit.ly/2NvvFS }\end{array}$ \\
\hline $25 / 03 / 2007$ & $\begin{array}{l}\text { Pouquíssimo destaque para "personagens" mulheres nos cadernos Ilustrada e Esportes. } \\
\text { https://bit.ly/2N2K4g3 }\end{array}$ \\
\hline 02/09/2007 & $\begin{array}{l}\text { Crítica às caricaturas estereotipadas de profissionais gays. } \\
\text { https://bit.ly/2puf } x 1 \mathrm{U}\end{array}$ \\
\hline
\end{tabular}


Quadro 1: Continuação

\begin{tabular}{|c|c|}
\hline Data & Problema criticado \\
\hline $04 / 11 / 2007$ & $\begin{array}{l}\text { Desigualdade entre mulheres (e negros) e homens (e brancos) até mesmo nos obituários. } \\
\text { https://bit.ly/2Wtv0eC }\end{array}$ \\
\hline $30 / 12 / 2007$ & $\begin{array}{l}\text { Falta de representatividade da diversidade racial nacional em cobertura de moda. } \\
\text { https://bit.ly/2PB2Xsu }\end{array}$ \\
\hline $01 / 03 / 2009$ & $\begin{array}{l}\text { Mulheres seminuas e vulgaridade costumeira na cobertura do carnaval. Destaque } \\
\text { exagerado para a cirurgia plástica de Dilma (sendo que políticos homens também fazem } \\
\text { modificações estéticas no próprio corpo e não merecem destaque). } \\
\text { https://bit.ly/36ilOOV }\end{array}$ \\
\hline $03 / 07 / 2011$ & $\begin{array}{l}\text { Hiperinflação de participantes em parada gay e acirramento entre os contrários à } \\
\text { "ditadura gay" e os favoráveis à ampliação do direito dessas minorias. } \\
\text { https://bit.ly/2Cbo10N }\end{array}$ \\
\hline $17 / 06 / 2012$ & $\begin{array}{l}\text { Cobertura da torcida corintiana em Parada Gay. } \\
\text { https://bit.ly/31Z6YsZ }\end{array}$ \\
\hline $30 / 09 / 2012$ & $\begin{array}{l}\text { Acusação de homofobia em duas notícias sobre novo jogador do São Paulo. } \\
\text { https://bit.ly/2q54PyX }\end{array}$ \\
\hline 09/06/2013 & $\begin{array}{l}\text { Nota machista sobre celulite de atleta. } \\
\text { https://bit.ly/2qWaK9K }\end{array}$ \\
\hline $03 / 11 / 2013$ & $\begin{array}{l}\text { Jovem negro detido, fotografado e tendo sua imagem na capa do jornal, associada ao crime. } \\
\text { https://bit.ly/2ptBYEn }\end{array}$ \\
\hline $29 / 12 / 2013$ & $\begin{array}{l}\text { Supressão do problema indígena em reportagem impressa sobre a construção da usina de } \\
\text { Belo Monte. } \\
\text { https://bit.ly/2C5gsIB }\end{array}$ \\
\hline $05 / 06 / 2016$ & $\begin{array}{l}\text { De que forma a cobertura contribui para reforçar a cultura do estupro. } \\
\text { https://bit.ly/34n7enr }\end{array}$ \\
\hline $21 / 08 / 2016$ & $\begin{array}{l}\text { Sexismo em cobertura das atletas olímpicas. } \\
\text { https://bit.ly/2Wtn2SE }\end{array}$ \\
\hline $22 / 01 / 2017$ & $\begin{array}{l}\text { Machismo em descrição de vítimas. } \\
\text { https://bit.ly/2WwhV4j }\end{array}$ \\
\hline $20 / 08 / 2017$ & $\begin{array}{l}\text { Uso do termo "racista" em vez de "supremacista" e risco da falsa equivalência. } \\
\text { https://bit.ly/2JCxnqk }\end{array}$ \\
\hline 03/09/2017 & $\begin{array}{l}\text { Problematização sobre a visibilidade das mulheres nas páginas da Folha. } \\
\text { https://bit.ly/2WEXoL7 }\end{array}$ \\
\hline $12 / 11 / 2017$ & $\begin{array}{l}\text { Tentativa de proteger Waack em cobertura sobre comentário racista. } \\
\text { https://bit.ly/34klr4t }\end{array}$ \\
\hline $19 / 11 / 2017$ & $\begin{array}{l}\text { Falta de cobertura das manifestações contra a PEC } 181 . \\
\text { https://bit.ly/36mF6T5 }\end{array}$ \\
\hline $18 / 03 / 2018$ & $\begin{array}{l}\text { Falta de destaque e demora para a contextualização do assassinato de Marielle e } \\
\text { Anderson. Ausência da dimensão negra e mulher na política. } \\
\text { https://bit.ly/34fUGOz }\end{array}$ \\
\hline $12 / 08 / 2018$ & $\begin{array}{l}\text { Descrição preconceituosa (sexista) de PM morta. } \\
\text { https://bit.ly/2NwzU6D }\end{array}$ \\
\hline $16 / 12 / 2018$ & $\begin{array}{l}\text { Risco de cumplicidade machista na divulgação de casos de assédio. } \\
\text { https://bit.ly/2NrRx7r }\end{array}$ \\
\hline $24 / 02 / 2019$ & $\begin{array}{l}\text { Falta de cobertura do assassinato de indígenas na fronteira com a Venezuela. } \\
\text { https://bit.ly/34mciZk }\end{array}$ \\
\hline
\end{tabular}

Fonte: Elaborado pela autora.

No decorrer desses quase trinta anos de publicação de colunas de ombudsman na Folha de S. Paulo, a cobertura jornalística sobre minorias foi criticada publicamente com uma frequência média de 1,4 vezes por ano, representando 2,9\% do total de temas que apareceram. Nos anos de 1997, 1998, 2000, 2003, 2008 e 2015, não foram identificados textos críticos à abordagem de indígenas, 
negros, mulheres e comunidade LGBTI+. Em 2017, houve o recorde de cinco colunas criticando a cobertura.

Aplicando as definições de Honneth (2009) acerca do reconhecimento não obtido na forma da exclusão ou da ofensa, contabiliza-se 39 colunas que avaliam a cobertura por essa perspectiva. Essas críticas abordam como as produções jornalísticas podem excluir ou ofender as minorias indígena, negra, mulher e LGBTI+. Em cinco casos, mais de uma das quatro minorias são excluídas ou ofendidas por uma mesma cobertura. Em seis situações, uma mesma cobertura ofende e exclui algum grupo minoritário - em produções que privilegiam a versão de criminosos (racistas ou estupradores), colocando em dúvida a versão da vítima e a culpabilizando, ou seja, negando seu direito de ter a queixa legitimada e provocando degradação de sua dignidade. Optou-se por dividir em três décadas o período analisado a fim de se perceber tendências que sinalizem mudanças nos critérios de crítica.

Quadro 2: Exclusão e/ou ofensa de minorias identificadas nas críticas

\begin{tabular}{|l|c|c|c|l|c|c|c|l|l|l|l|}
\hline \multicolumn{4}{|c|}{$1^{\text {a década }}$} & \multicolumn{4}{c|}{ 2 década $^{\text {a década }}$} \\
\hline Minoria & Exclusão & Ofensa & Total & Minoria & Exclusão & Ofensa & Total & Minoria & Exclusão & Ofensa & Total \\
\hline Indígena & 2 & 0 & 2 & Indígena & 3 & 0 & 3 & Indígena & 2 & 0 & 2 \\
\hline Negra & 2 & 5 & 7 & Negra & 5 & 2 & 7 & Negra & 3 & 4 & 7 \\
\hline Mulher & 0 & 4 & 4 & Mulher & 2 & 1 & 3 & Mulher & 5 & 6 & 11 \\
\hline LGBTI+ & 0 & 0 & 0 & LGBTI+ & 0 & 1 & 1 & LGBTI+ & 1 & 3 & 4 \\
\hline
\end{tabular}

Fonte: Elaborado pela autora.

As quatro primeiras críticas, no início da década de 1990, têm como tema a cobertura sobre problemas da comunidade negra nos Estados Unidos juízos possivelmente influenciados pelos encontros anuais da Organização de Ombudsmans da Imprensa (ONO, em inglês). Somente em julho de 1993, a coluna de ombudsman aborda uma publicação jornalística brasileira, apontando defeitos de um perfil que descreve de forma machista, racista e classista uma mulher japonesa que busca ascensão social. Vale aqui observar que as opressões se entrecruzam em outras quatro críticas: pela segunda vez, no ano de 1993, por causa da descrição preconceituosa de uma mulher negra; em 2007, pela falta 
de obituários sobre mulheres e negros/negras; em março e agosto de 2018, nas reportagens sobre os assassinatos da vereadora, mulher, negra e lésbica Marielle Franco e da policial militar, mulher, negra e lésbica Juliane dos Santos Duarte.

A cobertura sobre a minoria negra é a mais criticada nesses quase trinta anos - só fica abaixo da minoria mulher na terceira década ${ }^{9}$. Em dez colunas, a avaliação tem como tema a ausência de grupos e indivíduos negros nas produções jornalísticas. Em 11 críticas, a cobertura até conta com a presença de pessoas negras; porém, de uma maneira considerada ofensiva, preconceituosa. De acordo com os ombudsmans, o pico de exclusão ocorre entre 2000 e 2009 e o ponto mais alto das publicações discriminatórias é verificado entre 1990 e 1999 - número que diminui na década seguinte, mas volta a crescer entre 2010 e 2019. "Com raríssimas exceções, o racismo e suas mazelas não frequentam as pautas diárias, estão alijados de qualquer iniciativa regular e permanente", admitiu Ajzenberg (2001, s.p.).

Nesse sentido, um caso que demanda problematização maior é a coluna que tem como tema a identificação do novo diretor da Polícia Federal (PF) como "negro". Para dois leitores e a ombudsman, informar a raça/etnia do homem foi uma atitude de discriminação amparada pela maioria. "O quase silêncio mostra o quanto a sociedade brasileira é condescendente com manifestações de preconceito racial", avaliou Lo Prete (1999). O "jornal" argumentou que um negro assumir a direção da PF era um fato inédito. No parecer de Lo Prete (1999), o ineditismo só se justificaria caso fosse o "primeiro presidente, prefeito, general". Entretanto, na luta do movimento negro, a representatividade em todos os espaços é importante (RIBEIRO, 2017). É feita, porém, a ressalva: "o fato de uma pessoa ser negra não significa que ela saberá refletir crítica e filosoficamente sobre as consequências do racismo" (RIBEIRO, 2017, p. 67).

A solução para o impasse, nesse caso, talvez fosse manter contato com o diretor da PF e perguntar como ele se identifica, qual sua opinião sobre a 
reportagem, se percebe problemas nas relações entre negros e Polícia Federal e, em caso positivo, se pretende implementar alguma medida específica para melhorar a situação. Na análise da presença de minorias em filmes, Serelle e Sena (2018) lembram da importância de ouvir a voz das pessoas que se sentiram ofendidas em produções midiáticas e evitar a postura objetificante de "falar em nome de".

Mais um sinal que denota a complexidade do tema: em julho de 2006, a coluna de ombudsman critica o desequilíbrio da cobertura sobre a votação das políticas afirmativas e estatuto da igualdade racial. De acordo com a análise, o noticiário trazia mais pontos de vistas contrários à proposta de estabelecer, entre outras medidas, as cotas raciais - essa contrariedade coincidia com o posicionamento do jornal ${ }^{10}$ manifestado em três editoriais. A tentativa de corrigir o erro, ampliando o espaço para opiniões favoráveis, não foi suficiente. "A discussão sobre questões raciais é sempre difícil. Mas não é difícil fazer uma cobertura jornalística equilibrada e pluralista, que não se deixe contaminar pela opinião do jornal. Basta vigilância e vontade", concluiu, na época, Beraba (2006).

Sendo a segunda minoria cuja exclusão e/ou ofensa mais é criticada na Folha de S.Paulo, a mulher chega a ser tema de nove colunas na atual década um recorde comparado aos demais grupos. Inicialmente, não são feitas análises sobre a ausência de mulheres na cobertura, mas as quatro colunas de ombudsman abordam publicações jornalísticas ofensivas à comunidade feminina. Entre 2000 e 2009, diminui o número de críticas; porém, elas se tornam mais diversificadas e passam a ter como tema a exclusão de mulheres nos textos informativos. A partir de 2010, é verificado o aumento e maior equilíbrio das avaliações: cinco tratam da exclusão e seis dizem respeito à ofensa.

Na primeira década, somente duas críticas abordam a ausência de pautas sobre questões indígenas. A quantidade sobe para três nos dez anos seguintes e volta para duas entre 2010 e 2019. A minoria indígena é a segunda que 
menos aparece nas colunas e é a única que sempre está vinculada à exclusão. Esse dado demonstra a dificuldade que esse grupo enfrenta para conquistar reconhecimento no jornal de maior circulação no país para suas demandas. Em seus textos, profissionais de diferentes períodos apontaram essa tendência de a cobertura excluir temas como a luta pela demarcação de terras, as epidemias, a fome e outros tipos de violência que colocam as tribos em situação vulnerável. "Ombudsman também existe para falar do que ninguém quer ouvir. Índios, por exemplo. O tema deixou de ser 'in' há anos. A Folha insiste em negligenciá-lo, como na cobertura do polêmico decreto 1.775" (LEITE, 1996).

Sem referências na primeira década de coluna de ombudsman, a população LGBTI+ é a que menos aparece nas críticas. Entre 2000 e 2009, apenas uma avaliação acusou cobertura preconceituosa: ilustrações estereotipadas de profissionais gays em uma reportagem sobre pesquisa do Datafolha. Na década atual, quatro críticas apontam produções jornalísticas que excluem ou ofendem a minoria LGBTI+, sendo que, em dois casos, o noticiário trata de pessoas que são, além de lésbicas, mulheres e negras.

Assim, chama a atenção uma coluna de julho de 1995, com o que poderia ser considerada uma análise na contramão da luta de negros e comunidade LGBTI+. O ombudsman critica a artificialidade de uma pesquisa sobre racismo porque a compara com a denúncia de corrupção no aeroporto de Cumbica (considerada mais atual e merecedora de destaque na capa em relação a um problema que poderia ser diagnosticado em qualquer outro dia). Leite (1995) também questiona o que chama de exagero - 70 reportagens sobre homossexuais publicadas entre os dias 8 e 25 de junho, período em que foi realizada a 17a Conferência Mundial da Associação Internacional de Gays e Lésbicas no Rio de Janeiro: "haveria tanto interesse no assunto homossexualismo?".

Quase 15 anos depois, a cobertura da Parada Gay, em São Paulo, noticiava a presença de 4 milhões de participantes - número destacado em manchete divulgada no site. Apesar de contar com um instituto capaz de calcular a quantidade de pessoas em multidões, a Folha valeu-se da impressão de jornalistas responsáveis 
por registrar o evento. Segundo a ombudsman, a hiperinflação fomentou a suspeita de que a população LGBTI+ é privilegiada pelo jornal. "Desde a aprovação da união estável para homossexuais, se acirrou a batalha entre os que veem os perigos de uma 'ditadura gay' e os que pretendem ampliar os direitos dessa minoria", avaliou Singer (2011).

\section{Reconhecimento, crítica da cobertura e compreensão da sociedade}

Considerando estudos apresentados anteriormente, é possível afirmar que a sociedade brasileira está sendo constituída por meio de lutas pelo reconhecimento das demandas de indígenas, negros, mulheres e comunidade LGBTI+. Na recente história do maior país da América do Sul, há registros de muitas conquistas desses grupos minoritários - incluindo uma maior visibilidade para suas causas e veiculação de imagens menos negativas na mídia. Desde o final do século XIX, por influência de movimentos internacionais, indivíduos e grupos marginalizados querem ampliar seu espaço midiático a fim de sensibilizar mais pessoas e promover avanços políticos.

Sabe-se do papel fundamental da mídia para constituir identidades, reforçando os preconceitos ou propondo a diversidade - entendimento que parece ser compartilhado pelos críticos especializados da Folha, como nota-se na avaliação de Costa (2017): "questões que envolvem gênero, raça ou classe são das que mais mobilizam os leitores. Estão no cerne da discussão moderna sobre como cada um constrói a sua identidade". Sendo o jornalismo produto e produtor de cultura (SOARES; SILVA, 2016), a crítica da cobertura jornalística tende a receber interferência dos valores sociais. No caso das 41 colunas aqui analisadas, a maior parte delas (21) foi originada explicitamente de manifestações do público. Mesmo que não tivesse sido assim, as bases teóricas permitem afirmar que as avaliações individuais do/da ombudsman partem de elementos constituídos socialmente.

Embora não utilizem o termo, ombudsme criticam a exclusão e a ofensa em produções jornalísticas - formas, segundo Honneth (2009), de negar o reconhecimento das demandas minoritárias. É o que pode ser verificado no trecho que 
analisa o perfil da policial militar Juliane dos Santos Duarte (mulher, negra e lésbica), publicado após seu assassinato, em agosto de 2018. "A reportagem foi considerada 'preconceituosa', 'desrespeitosa', 'difamatória'", escreveu Costa (2018), repercutindo, em sua coluna, as manifestações de leitores que consideraram o texto ofensivo. Outro exemplo ocorre quando Santos (1993) critica a cobertura que corrobora a exclusão, nesse caso, deixando de incluir problemas indígenas no noticiário ou abdicando do dever de apurá-los com rigor:

Dez dias depois de que a notícia veio a público através da Funai, o país ainda não sabe ao certo o que aconteceu na aldeia Haximu, dos ianomâmis. A imprensa e o governo não conseguiram levantar evidências a respeito da extensão do massacre, de seus autores e motivações. [...] Seja qual for o motivo, parece não ter havido do governo e da imprensa interesse em checar a materialidade das versões apresentadas.

Conforme já referenciado, indígenas, negros, mulheres e LGBTIs+ querem estar mais presentes na imprensa e querem que essa presença expresse o respeito pelas diferenças (CANABARRO, 2013; GOMES, 2017; MUNDURUKU, 2015; PINTO, 2003). Quando ocorre a ausência ou a visibilidade negativa desses grupos, ombudsmans tendem a acusar o erro dos textos informativos e refletir acerca dos preconceitos de jornalistas.

É necessário, no entanto, ponderar sobre os limites dessa crítica, lembrando três aspectos da condição de ombudsman: a) como membros de uma sociedade preconceituosa, podem ser, eles mesmos, preconceituosos; b) por serem jornalistas, podem estar propensos a defender colegas de profissão e; c) trata-se de funcionários(as) do jornal que criticam o próprio veículo e precisam lidar com os constrangimentos dessa situação. Cabe questionar, ainda, se essa manifestação de autocrítica não atende a um acordo não verbalizado entre produtores e audiência, que prevê limites muito bem demarcados para juízos contundentes. Considerando o perfil de quem lê a Folha de S.Paulo ${ }^{11}$, pode-se supor que é compartilhado entre diretores da empresa, jornalistas e leitores um desejo de atenuar posicionamentos 
contrários à maioria masculina das classes A e B a fim de não provocar demasiados desconfortos. Também vale o cuidado com o anacronismo ao olhar para as colunas, pois o entendimento que se tem em 2019 sobre a forma de abordar minorias passou por significativas transformações desde 1990.

Percebe-se, com esta análise, que o conceito de reconhecimento tem grande potencialidade para ser trabalhado em outras críticas (por exemplo, aquelas feitas por acadêmicos, outros especialistas e, principalmente, pelo público) da cobertura jornalística de grupos minoritários (pessoas com deficiência, moradores de periferia...). Como teoria social, portanto, que auxilia na compreensão de fenômenos da sociedade, o estudo de reconhecimento pode ajudar a entender produções jornalísticas e suas respectivas críticas, uma vez que estão imersas no ambiente social, tanto como resultado dele como contribuindo para formá-lo em toda a sua diversidade e limitações.

\section{Referências}

AJZENBERG, B. Os invisíveis. Folha de S.Paulo, São Paulo, 26 ago. 2001. Disponível em: https://bit.ly/335A0si. Acesso em: 18 out. 2019.

AZEREDO, D. A contribuição da coluna de ombudsman para a compreensão do acontecimento no caso da morte do reitor Cancellier. In: HRENECHEN, V. C. A. T. (org.). Comunicação e jornalismo: conceitos e tendências. 3. ed. Ponta Grossa: Atena, 2019. p. 1-11.

BERABA, M. Ações afirmativas. Folha de S.Paulo, São Paulo, 9 jul. 2006. Disponível em: https://bit.ly/2NtVh8v. Acesso em: 18 out. 2019.

CANABARRO, R. História e direitos sexuais no Brasil: o movimento LGBT e a discussão sobre a cidadania. In: Congresso Internacional de História Regional, 2., 2013, Passo Fundo. Anais... Passo Fundo: UPF, 2013. p. 1-15. 
COSTA, C. T. Uma barrida e duas lições. Folha de S.Paulo, São Paulo, 28 jan. 1990. Disponível em: https://bit.ly/3201dvm. Acesso em: 30 out. 2019.

COSTA, P. C. Âncoras ao mar. Folha de S. Paulo, São Paulo, 19 nov. 2017. Disponível em: https://bit.ly/2Py7pIk. Acesso em: 18 out. 2019.

COSTA, P. C. Beijos fora do lugar. Folha de S.Paulo, São Paulo, 12 ago. 2018. Disponível em: https://bit.ly/2PDs39V. Acesso em: 18 out. 2019.

FREIRE FILHO, J. Mídia, Estereótipo e Representação das Minorias. ECO-PÓS, Rio de Janeiro, v. 7, n. 2, 2004.

GOMES, N. L. O movimento negro educador: saberes construídos nas lutas por emancipação. Petrópolis: Vozes, 2017.

HONNETH, A. Luta por reconhecimento: a gramática moral dos conflitos sociais. São Paulo: Editora 34, 2009.

KELLNER, D. A cultura da mídia: estudos culturais - identidade e política entre o moderno e o pós-moderno. Bauru: EDUSC, 2001.

LEITE, M. Domingão no aeroporto. Folha de S.Paulo, São Paulo, 2 jul. 1995. Disponível em: https://bit.ly/34fUu1N. Acesso em: 18 out. 2019.

LEITE, M. Tembés, Uapixanas, Maxacalis e outros bichos. Folha de S.Paulo, São Paulo, 21 jan. 1996. Disponível em: https://bit.ly/2BXcgL6. Acesso em: 18 out. 2019.

LO PRETE, R. Que é negro. Folha de S.Paulo, São Paulo, 11 jul. 1999. Disponível em: https://bit.ly/34hi1i]. Acesso em: 18 out. 2019. 
MONTEIRO, J. M. Negros da terra: índios e bandeirantes nas origens de São Paulo. São Paulo: Companhia das Letras, 1994.

MUNDURUKU, D. O banquete dos deuses: conversa sobre a origem e a cultura brasileira. São Paulo: Global Editora, 2015.

PINTO, C. R. J. Uma história do feminismo no Brasil. São Paulo: Editora Fundação Perseu Abramo, 2003.

RIBEIRO, D. O que é lugar de fala? Belo Horizonte: Letramento, 2017.

SANTOS, M. V. Mistério na aldeia. Folha de S.Paulo, São Paulo, 29 ago. 1993. Disponível em: https://bit.ly/36vPSXo. Acesso em: 18 out. 2019.

SERELLE, M.; SENA, E. Crítica e reconhecimento: lutas identitárias na cultura midiática. In: Encontro Anual da Compós, 27., 2018, Belo Horizonte. Anais [...]. Belo Horizonte: Compós, 2018. p. 1-20.

SINGER, S. Será que a Folha é? Folha de S.Paulo, São Paulo, 17 jun. 2012. Disponível em: https://bit.ly/31WAKyI. Acesso em: 18 out. 2019.

SOARES, R. L.; SILVA, G. Lugares da crítica na cultura midiática. Comunicação, Mídia e Consumo, São Paulo, v. 13, n. 37, 2016.

submetido em: 6 ago. 2019 | aprovado em: 7 set. 2019 